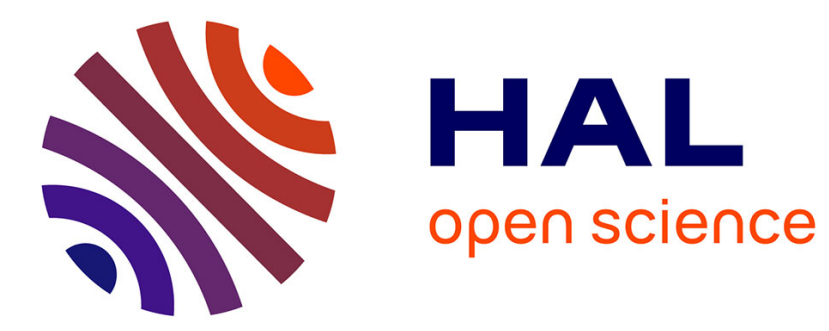

\title{
Comments on the "Influence of the load modelling during gait on the stress distribution in a femoral implant" by Gervais et al.
}

Raphaël Dumas

\section{To cite this version:}

Raphaël Dumas. Comments on the "Influence of the load modelling during gait on the stress distribution in a femoral implant" by Gervais et al.. Multibody System Dynamics, 2019, 47 (4), pp. 435-437. 10.1007/s11044-019-09709-w . hal-02383849

\section{HAL Id: hal-02383849 \\ https://hal.science/hal-02383849}

Submitted on 28 Nov 2019

HAL is a multi-disciplinary open access archive for the deposit and dissemination of scientific research documents, whether they are published or not. The documents may come from teaching and research institutions in France or abroad, or from public or private research centers.
L'archive ouverte pluridisciplinaire HAL, est destinée au dépôt et à la diffusion de documents scientifiques de niveau recherche, publiés ou non, émanant des établissements d'enseignement et de recherche français ou étrangers, des laboratoires publics ou privés. 


\section{Comments on the "Influence of the load modelling during gait on the stress distribution in a femoral implant" by Gervais et al.}

Raphael Dumas

Univ Lyon, Université Claude Bernard Lyon 1, IFSTTAR, LBMC UMR_T9406, 69622 Lyon, France

Gervais et al. [1] have recently published in the Multibody System Dynamics journal a study entitled "Influence of the load modelling during gait on the stress distribution in a femoral implant" where they put forward an interesting inverse dynamics method with flexible bony segments in order to estimate the loads applied to a femoral implant. They have compared different static and dynamic methods to estimate the joint loads required as boundary conditions for a finite element analysis of the implant. These joint loads are obtained either by considering the body weight in a static condition or by computing the inter-segmental forces and moments using inverse dynamics.

It seems that the authors did not really distinguish the inter-segmental forces and moments from the loads transmitted to the joints or to the bony segments. However, in biomechanics, the intersegmental forces and the forces transmitted to the joints (generally designated as joint reaction forces, joint or articular contact forces) are two different things.

Inter-segmental forces and moments

From an external point of view, the inter-segmental forces and moments represent the resultant of the contact actions of the body with the environment (typically at the foot-ground contact), as well as the gravitational, centrifugal and Coriolis actions arising from motion of the segments. These are the forces and moments computed by inverse dynamics, and in the paper of Gervais et al. [1], efficiently computed with flexible multibody dynamics.

Though, from an internal point of view, these inter-segmental forces and moments represent the resultant of the mechanical actions of all the anatomical structures crossing the joint: skin, fat, facias, 
bi- and mono-articular muscles, ligaments and articular surfaces. The loads transmitted to the joints correspond to the articular contact forces. That is, the loads transmitted to the joints represent a component of the inter-segmental forces and moments, a component which cannot be obtained without taking into account the actions of the muscles (and of the ligaments and other passive structures, but which are neglected most of the time).

\section{Forces transmitted to the joints and bony segments}

Not only 1 body weight (BW) but 2.5 BW have been considered an "improved static" loading conditions of the implant, as explained by the authors [1], based on in vivo instrumented prosthesis measurements [2]. The same rationale could have been followed for the dynamic loading conditions. For gait, in vivo measurements from instrumented implants $[3,4]$ as well as simulation results from musculoskeletal models $[5,6]$ have reported 2 to 4 BW of compression of the femur. Similar measurements and results have reported hip and knee contact forces in the same range, e.g. $[7,8]$. Furthermore, modelling studies have demonstrated that the forces transmitted to the joints and bony segments are mainly due to the contributions of the muscle actions (e.g. rectus femoris and hamstrings) $[9,10]$ as opposed to gravitational, centrifugal and Coriolis actions. That is why musculotendon forces have to be taken into account, like in previous musculoskeletal models with flexible bony segments, e.g. [11]. In other words, the muscle actions should not be omitted when estimating the stress or strain in the bone or the implant.

It is only in the case of lower limb amputees, e.g. transfemoral amputees with osteo-integrated implants measured in vivo using embedded sensors [12], that the forces transmitted to the bony segments remain of $1 \mathrm{BW}$ during gait. In this case, the flexible inverse dynamics proposed by Gervais et al. [1] would perfectly apply, typically because the prosthetic component include deformable parts and because the classical inverse dynamics methods has been found inaccurate in this case $[13,14]$. 


\section{References}

1. Gervais, B., Vadean, A., Brochu, M., Raison, M.: Influence of the load modelling during gait on the stress distribution in a femoral implant. Multibody System Dynamics In press (2018). doi:10.1007/s11044-018-9621-z

2. Bergmann, G., Deuretzbacher, G., Heller, M., Graichen, F., Rohlmann, A., Strauss, J., Duda, G.N.: Hip contact forces and gait patterns from routine activities. Journal of Biomechanics 34(7), 859871 (2001). doi:https://doi.org/10.1016/S0021-9290(01)00040-9

3. Lu, T.-W., Taylor, S.J.G., O'Connor, J.J., Walker, P.S.: Influence of muscle activity on the forces in the femur: An in vivo study. Journal of Biomechanics 30(11), 1101-1106 (1997). doi:https://doi.org/10.1016/S0021-9290(97)00090-0

4. Taylor, S.J.G., Walker, P.S., Perry, J.S., Cannon, S.R., Woledge, R.: The forces in the distal femur and the knee during walking and other activities measured by telemetry. The Journal of Arthroplasty 13(4), 428-437 (1998). doi:https://doi.org/10.1016/S0883-5403(98)90009-2

5. Duda, G.N., Schneider, E., Chao, E.Y.S.: Internal forces and moments in the femur during walking. Journal of Biomechanics 30(9), 933-941 (1997). doi:https://doi.org/10.1016/S0021$\underline{9290(97) 00057-2}$

6. Moissenet, F., Chèze, L., Dumas, R.: A 3D lower limb musculoskeletal model for simultaneous estimation of musculo-tendon, joint contact, ligament and bone forces during gait. Journal of Biomechanics 47(1), 50-58 (2014). doi:https://doi.org/10.1016/i.jbiomech.2013.10.015

7. Kinney, A.L., Besier, T.F., D'Lima, D.D., Fregly, B.J.: Update on Grand Challenge Competition to Predict in Vivo Knee Loads. Journal of Biomechanical Engineering 135(2), 021012-021012-021014 (2013). doi:10.1115/1.4023255

8. Modenese, L., Phillips, A.T.M.: Prediction of hip contact forces and muscle activations during walking at different speeds. Multibody System Dynamics 28(1), 157-168 (2012). doi:10.1007/s11044011-9274-7 
9. Moissenet, F., Chèze, L., Dumas, R.: Individual muscle contributions to ground reaction and to joint contact, ligament and bone forces during normal gait. Multibody System Dynamics 40(2), 193211 (2017). doi:10.1007/s11044-017-9564-9

10. Pandy, M.G., Andriacchi, T.P.: Muscle and joint function in human locomotion. Annual review of biomedical engineering 12, 401-433 (2010). doi:10.1146/annurev-bioeng-070909-105259

11. Kłodowski, A., Rantalainen, T., Mikkola, A., Heinonen, A., Sievänen, H.: Flexible multibody approach in forward dynamic simulation of locomotive strains in human skeleton with flexible lower body bones. Multibody System Dynamics 25(4), 395-409 (2011). doi:10.1007/s11044-010$9240-9$

12. Lee, W.C.C., Frossard, L.A., Hagberg, K., Haggstrom, E., Gow, D.L., Gray, S., Brånemark, R.: Magnitude and variability of loading on the osseointegrated implant of transfemoral amputees during walking. Medical Engineering \& Physics 30(7), 825-833 (2008). doi:https://doi.org/10.1016/j.medengphy.2007.09.003

13. Dumas, R., Brånemark, R., Frossard, L.: Gait Analysis of Transfemoral Amputees: Errors in Inverse Dynamics Are Substantial and Depend on Prosthetic Design. IEEE Transactions on Neural Systems and Rehabilitation Engineering 25(6), 679-685 (2017). doi:10.1109/TNSRE.2016.2601378

14. Schwarze, M., Hurschler, C., Seehaus, F., Oehler, S., Welke, B.: Loads on the prosthesis-socket interface of above-knee amputees during normal gait: Validation of a multi-body simulation. $\begin{array}{llll}\text { Journal of } & \text { Biomechanics } & \text { 46(6), } & \text { 12013). }\end{array}$ doi:https://doi.org/10.1016/j.jbiomech.2013.02.005 